\title{
Intrapleural Corynebacterium parvum for malignant pleural effusions
}

\author{
RAFFAELLA FELLETTI, CESARE RAVAZZONI
}

From the Ist Department of Chest Diseases, Ospedale Civile Regionale San Martino, Genoa, Italy

\begin{abstract}
A pilot study of topical (intrapleural) treatment with Corynebacterium parvum was carried out in 10 patients with malignant pleural effusions complicating primary or secondary neoplasms and necessitating frequent thoracocentesis for symptomatic relief. The method was aspiration of all intrapleural fluid except a small portion left for dilution, and then injection of $7 \mathrm{mg}$ of a preparation of Corynebacterium parvum suspended in $20 \mathrm{ml}$ of normal saline solution. The treatment was repeated in each case as clinical conditions called for further thoracocentesis. In eight of these 10 patients the treatment resulted in prompt reduction of the rate of accumulation of pleural fluid and a striking change of cell sediment composition, with appreciable reduction in or complete disappearance of malignant cells and a rise in lymphocyte and neutrophil polymorph counts. The best responders were patients with primary pleural mesothelioma. Clinical improvement was evident in all responders.
\end{abstract}

The control of primary or secondary pleural effusions in patients with neoplasms constitutes a major clinical problem. The many drugs and physical agents that have been tried in the hope of stopping or at least slowing down the rate of accumulation include radioactive colloidal gold, ${ }^{1}$ talc, ${ }^{2}$ doxorubicin, ${ }^{34}$ quinacrine, $^{5}$ tetracycline, ${ }^{6}$ nitrogen mustard, ${ }^{7}$ and bleomycin. ${ }^{8}$ The clinical results have been variable, with considerable side effects in some instances.

Recently attempts have been made to control the effusions with substances that besides producing pleural fibrosis might exert an immune-stimulating action at the site of pleural effusion. After completing a series of animal studies with intrapleural Corynebacterium parvum Israël's group proposed intracavitary treatment with this agent for neoplastic effusions. ${ }^{9}{ }^{10}$ Grant $^{12}$ conducted a comparative trial of intrapleural mustine hydrochloride versus Corynebacterium parvum and showed favourable results with the latter. Another report, ${ }^{13}$ on six patients with neoplastic pleurisy or ascites, described good results in six cases, with quantitative reduction of effusion fluids and reduced malignant cell counts. In view of these reports we decided to attempt to verify the fibrosing and immunostimulant effects of intrapleural Corynebacterium parvum in our own patients. Ten patients were studied-four with secondary neoplastic pleurisy (three with lung carcinoma and one

Address for reprint requests: Dr R Felletti, 1st Department of Chest Diseases, Ospedale Civile Regionale San Martino. Genoa, Italy. with ovarian adenocarcinoma), five with primary pleural mesothelioma, and one with an exclusively pleuropulmonary lymphoblastic lymphoma.

\section{Methods}

The patients were accepted for the Corynebac-

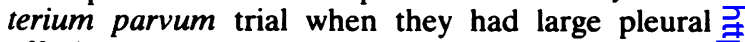
effusions necessitating frequent thoracocentesis for the relief of severe cough, dyspnoea, and pain. The neoplastic nature of these pleural effusions was 을 ascertained by pleural biopsy in the five cases of $\underset{x}{\infty}$ primary neoplasms and confirmed by the detection of $\frac{5}{3}$ tumour cells in pleural fluids in the others. The diagnosis of mesothelioma was made histologically from needle biopsy specimens on the basis of the characteristic epithelial arrangements (tubulo- 음 papillary patterns) of the neoplastic cells, with scanty $\frac{7}{2}$ eosinophilic cytoplasm and an ovoid nucleus with well-developed nucleolus.

All 10 patients gave their informed consent in writing. The method consisted of draining as much pleural fluid as possible except the last $100 \mathrm{ml}$ or so, $\mathrm{\omega}$ and then injecting into the pleural cavity $7 \mathrm{mg}$ of Corynebacterium parvum (Coparvax Wellcome: vial oo containing $7 \mathrm{mg}$ (dry weight) of the killed Corynebacterium parvum organisms, Wellcome $\stackrel{\mathscr{?}}{+}$ strain CN6134, in a freeze-dried form); this was 7 suspended in $20 \mathrm{ml}$ of normal saline solution. There $\overrightarrow{\mathrm{D}}$ was no predetermined rate of further administration: $\stackrel{\Phi}{\Omega}$ each patient was treated as dictated by the amount of $\stackrel{\Phi}{\varrho}$ pleural fluid reforming after each thoracocentesis. In 
Table 1 Patients treated with intrapleural Corynebacterium parvum (CBP): dosage and results

\begin{tabular}{|c|c|c|c|c|c|c|}
\hline Patient No & Diagnosis & Asbestos exposure* & $\begin{array}{l}\text { No of doses of } \\
C B P\end{array}$ & Result* & Previous aspirates & $\begin{array}{l}\text { Length of } \\
\text { follow-up } \\
\text { (weeks) }\end{array}$ \\
\hline $\begin{array}{l}1 \\
2 \\
3 \\
4 \\
5\end{array}$ & $\begin{array}{c}\text { Mesothelioma } \\
\text {," } \\
\text { ", } \\
\text {," }\end{array}$ & $\begin{array}{l}20 \mathrm{y} \\
8 \mathrm{y} \\
20 \mathrm{y} \\
\text { Unknown } \\
\text { Unknown }\end{array}$ & $\begin{array}{l}1 \\
2 \\
2 \\
2 \\
2\end{array}$ & $\begin{array}{l}\text { CS } \\
\text { CS } \\
\text { CS } \\
\text { CS } \\
\text { CS }\end{array}$ & $\begin{array}{l}\text { Weekly } \\
\text { Weekly } \\
\text { Weekly } \\
\text { Every two weeks } \\
\text { Every two weeks }\end{array}$ & $\begin{array}{l}5 \text { (died) } \\
36 \\
40 \\
36 \\
38\end{array}$ \\
\hline 6 & $\begin{array}{l}\text { Lymphoblastic lymphoma } \\
\text { (exclusive pulmonary } \\
\text { localisation) }\end{array}$ & & 2 & CS & & \\
\hline 7 & Metastatic lung carcinoma & & 1 & $\mathbf{U}$ & & \\
\hline 8 & , & & 1 & CS & & \\
\hline 9 & , & & 4 & PS & & \\
\hline 10 & Metastatic ovarian carcinoma & & 2 & CS & & \\
\hline
\end{tabular}

* CS—completely successful; PS—partially successful; U—unsuccessful.

Patients $1-3$ worked for a long time in shipyards; for patients 4 and 5 there was no information about asbestos exposure, but their husbands had worked in shipyards.

most cases (eight out of 10 patients) the average interval between treatments was seven to 10 days.

The results were assessed as follows: $1-$ completely successful: total resolution of pleural effusion with fibrosis (without recurrence); 2-partially successful: reduction of volume of pleural effusion by half, doubling of the time interval between consecutive thoracocenteses (as dictated by clinical needs), or both; 3-unsuccessful: unchanged rate of accumulation of pleural fluid with no reduction of intervals between thoracocenteses.

\section{Results}

\section{RESPONSE OF PLEURAL EFFUSION TO \\ CORYNEBACTERIUM PARVUM}

Of 10 patients, eight had a complete response to intrapleural Corynebacterium parvum with no recurrence of pleural effusion during the rest of the period of follow-up. One patient had a partial response and one failed to respond. Details of the responses are given in table 1 . Of special interest is the fact that complete responses were seen in each of five patients with mesothelioma. These patients (three men and two women, aged 46-78) all had longstanding pleural effusions which had required repeated thoracocentesis over many months. The diagnosis of mesothelioma was established in all of them by pleural biopsy. In each case only one or two instillations of Corynebacterium parvum were required before the pleural effusion disappeared. In no case had the effusion returned during a follow-up period of five to 40 weeks.

\section{SIDE EFFECTS OF CORYNEBACTERIUM PARVUM}

Side effects from intrapleural Corynebacterium parvum (table 2) were considered acceptable. Six patients had mild fever (up to $38^{\circ} \mathrm{C}$ ) for one or two
Table 2 Side effects in patients treated with intrapleural Corynebacterium parvum

\begin{tabular}{llll}
\hline $\begin{array}{l}\text { Patient } \\
\text { No }\end{array}$ & Fever & Pain & Other complications \\
\hline 1 & Moderate & Moderate & \\
2 & No & No & \\
3 & Moderate & No & \\
4 & No & No & \\
5 & Moderate & No & \\
6 & Moderate & Moderate & \\
7 & No & No & \\
8 & High & Moderate & Acute bronchopneumonia \\
9 & Mild & Moderate Empyema \\
10 & Mild & Moderate & \\
\hline
\end{tabular}

days after treatment, readily controlled with aspirin. Two patients complained of fairly severe pain, which abated with analgesics. No patient had nausea or vomiting. One patient, with neoplastic pleurisy secondary to cancer of the lung and a postmyocardial infarct septal aneurysm, developed cardiovascular collapse with pain and high fever after treatment. There was clinical and radiological evidence of basal bronchopneumonia, which resolved promptly with a broad-spectrum antibiotic, while the pain was effectively controlled with analgesics. The acute episode was over in three days and the patient continued free of fever and pain; pleural effusion has not recurred.

\section{CYTOLOGICAL AND MORPHOLOGICAL CHANGES}

AFTER CORYNEBACTERIUM PARVUM

In three cases of mesothelioma the pleural fluid was examined at each aspiration for the presence of malignant cells. All these patients had malignant mesothelial cells before the Corynebacterium parvum treatment but after the first injection neoplastic cells could not be found in any of them. The effusions then contained large numbers of macrophages and neutrophils. In the patient with lymphoma the pleural 
effusion contained many atypical mononuclear cells, which disappeared after two injections of Corynebacterium parvum.

Corynebacterium parvum treatment appeared to produce an intense fibrotic reaction in the pleural space. One patient (case 1) died after five weeks and at necropsy the pleura was thickened and stiff with fibrous tissue. In another patient radiological evidence suggestive of fibrosis developed. In three patients further attempts at thoracocentesis gave dry taps with tough, thickened pleura.

\section{Discussion}

Out of 10 patients treated with intrapleural Corynebacterium parvum in this series eight were completely free of pleural effusion. Of the remaining two, one died from neoplastic cachexia about two weeks after treatment and was rated as a failure, though he had not required further thoracocentesis. The other, still in hospital and continuing treatment, has developed an empyema and is rated as a "partially successful" case since the amount of pleural effusion decreased, the intervals between thoracocenteses as dictated by clinical needs are longer, and neoplastic cells have disappeared from sediments. The mode of action of Corynebacterium parvum is not completely clear. When instilled into the pleural space it clearly excites an intense inflammatory response leading to fibrosis. Possibly part of its effect is a direct antitumour action-for example through activation of macrophages or of "natural killer" cells. ${ }^{14}$ is

These clinical results may be considered encouraging, even though the number of cases is small and follow-up is still in progress. Since in addition the method is not unduly laborious and the side effects are mild and easily controlled with simple remedies, we believe that intrapleural Corynebacterium parvum treatment for primary or secondary neoplastic pleurisy should be used more extensively.

\section{References}

' Botsford TW. Experience with radioactive colloidal gold in the treatment of pleural effusions caused by metastatic cancer of the breast. $N$ Engl J Med 1964;270:552-5.

2 Jones GR. Treatment of recurrent malignant pleural effusion by iodised talc pleurodesis. Thorax 1969;24:69-73.

${ }^{3}$ Desai SD, Figueredo A. Intracavitary doxorubicin in malignant effusion. Lancet 1979; i:872.

${ }^{4}$ Tattersall MHN, Fox RM, Newlands ES, Woods RL. Intracavitary doxorubicin in malignant effusions. Lancet 1979;;:390.

s Stiksa G, Korsgaard R, Simonsson BG. Treatment of recurrent pleural effusion by pleurodesis with quinacrine. Scand J Respir Dis 1979;60:197-205.

- Bayly TC, Kinser DL, Sybert A, MacDonald JS, Tsou E, N Schein P. Tetracycline and quinacrine in the control of malignant pleural effusions. Cancer 1978;41:1188-92.

${ }^{7}$ Mark JBD, Goldenberg IS, Montague AC. Intrapleural mechloroethamine hydrochloride therapy for malignant pleural effusion. JAMA 1964;187:858-60.

${ }^{8}$ Trotter JM, Stuart JFB, McBeth FR, McVie JG, Calman JC. The management of malignant effusions with bleomycin. Br J Cancer 1979;40:310.

9 Israël L, Halpern B. Le Corynebacterium parvum dans les cancers avancés. Nouv Presse Med 1972;1:19-23.

${ }^{10}$ Serrou P, Coupissol D, Israël L. Epanchements pleuraux traitement local par CBP. Nouv Presse Med 1980;25:1777-8.

$"$ Millar JW, Hunter AM, Horne NW. Intrapleural immunotherapy with $\mathrm{CBP}$ in recurrent malignant pleural effusions. Thorax 1980;35:856-8.

${ }^{12}$ Grant IWB. Intrapleural immunotherapy with CBP in recurrent malignant pleural effusions. Thorax 1981;36:319-20.

${ }^{13}$ Webb HE, Oaten SW, Pike CP. Treatment of malignant ascitic and pleural effusion with CBP. $\mathrm{Br}$ Med $J$ 1978;i:338-40.

14 Thatcher N, Lamb B, Swindell R, Crowther D. Effects of CBP on cellular immunity of cancer patients, assayed sequentially over 63 days. Cancer 1981;47:285-90.

15 Mantovani A, Sessa C, Peri G, Allavena P, Introna M, Polentarutti N, Mangioni C. Intraperitoneal administration of CBP in patients with ascitic ovarian tumours resistant to chemotherapy: effects on cytotoxicity on tumour-associated macrophages and NK cells. Int $J$ Cancer 1981;27:437-46. 


\section{Notices}

\section{Symposium on death from asthma}

A symposium entitled "Death from Asthma-Can We Prevent It?" that is to be held at East Birmingham Hospital Postgraduate Medical Centre on 13 July 1983 will be of interest to everyone concerned with the management of patients with asthma. The topics will include the recognition of asthma from a clinical and pathological viewpoint, a coroner's impression, lessons from the studies on deaths from asthma, patient education, emergency treatment, and self-referral schemes. Speakers will include Drs Alistair Brewis and Fleming Carswell, Professor Tim Clark, Drs Michael Dunnill, Andrew Johnson, David Stableforth and Charles Stewart, and Mr Andrew Nunn. Further details from Miss MC Wood, Postgraduate Medical Centre, East Birmingham Hospital, Bordesley Green East, Birmingham B9 5ST.

\section{European Working Group for Cystic Fibrosis}

The 12th annual meeting of the European Working Group for Cystic Fibrosis will be held in Athens, Greece, on 3-4 October 1983. This meeting will be preceded on 1-2 October by the annual meeting of the International Cystic Fibrosis (Mucoviscidosis) Association at the same venue. Further information from Ron Tucker, Executive Director, Cystic Fibrosis Research Trust, Alexandra House, 5 Blyth Road, Bromley, Kent BR1 3RS.

\section{Fifth International Congress of Laser Medicine and Surgery}

The Fifth International Congress of Laser Medicine and Surgery, sponsored jointly by Sinai Hospital of Detroit and the International Society of Laser Medicine and Surgery, will be held at the Westin Hotel in Detroit's Renaissance Center from 7 to 9 October 1983, and will include an extensive display of technical and scientific laser exhibits. The subjects to be covered include bronchoscopy and cardiovascular applications. Further information may be obtained from Sinai Hospital of Detroit or from the
Registration Supervisor, Fifth International Congress of Laser Medicine and Surgery, Charles B Slack Inc, 6900 Grove Road, Thorofare, New Jersey 08086, USA.

\section{Dr Alexander Capes Memorial Fund}

Applications are invited from nurses for a grant from the Dr Alexander Capes Memorial Fund to help them enlarge their experience in thoracic nursing. Consideration will be given to applicants from Britain wishing to study at other centres at home or abroad and to overseas applicants who wish to study in Britain and return home afterwards. Applications, giving details of the proposed study, should be sent to the Administrative Secretary, British Thoracic Society, 30 Britten Street, London SW3 6NN, by 16 June. June.

\section{Corrections}

\section{Intrapleural Corynebacterium parvum for malignant pleural efiusions}

In the paper by Drs R Felletti and C Ravazzoni (January p 22) work attributed to Grant ${ }^{12}$ in line 8 of the second paragraph should have been attributed thus: "Millar et al" conducted a comparative trial of intrapleural mustine hydrochloride versus Corynebacterium parvum and showed favourable results with the latter." The reference to Grant applies to a letter about the paper by Miller et al published with a reply from the authors.

Beta-blockers in bronchial asthma: efiect of propranolol and pindolol on large and small airways

In the paper by Dr D Patakas et al which appeared in the February issue (p 108) it was reported in the abstract and in table 2 that PEFR had fallen by $87.4 \% \pm 13 \cdot 2 \%$. This should have been $12 \cdot 6 \% \pm 1 \cdot 6 \%$. 